\title{
Methodology for Ensuring the Required Level of Traffic Safety at Single-Level Regulated Roads Intersections
}

\author{
Anatoly Plotnikov ${ }^{1 *}$, and Dmitry Gurin ${ }^{1}$ \\ ${ }^{1}$ Saint Petersburg State University of Architecture and Civil Engineering, 4, 2-ya Krasnoarmeyskaya \\ str, Saint Petersburg, 190005, Russia
}

\begin{abstract}
A functional flowchart is presented for the results of the investigations aimed at development of the methodology for automated control systems (ACS) which could evaluate and maintain the required traffic safety (TrS). The flowchart can be used in traffic management schemes (TMS) at regulated (signal-controlled) road intersections (RRI) with various methods of traffic light control in the options with traditional control methods I (phase by phase control) or II (control according to separate directions of traffic) and a new method of combined control of traffic III (various combinations of traditional methods I and II in one cycle of traffic light control). The control methods in ACS at RRI are changed according to the intensity threshold of left-turning and right-turning traffic streams to ensure the traffic safety $(\mathrm{TrS})$ during these maneuvers.
\end{abstract}

\section{Introduction}

Figure 1 represents the variability in statistics of the lethal cases occurred in road accidents (RA) during the latest 29 years in the territory of the Russian Federation (RF) after its targeted-oriented processing in absolute and relative units.

According to the road traffic accidents statistics out of the total number of road traffic accidents in the RF - 173,700 people in the year of 2016 alone 20,308 people were killed and 221,140 people were wounded. Every year more than 8,000 pedestrians are killed and more than 55,000 wounded in road accidents in the RF.

\section{Theory}

Social and economic losses from deaths in road traffic accidents in the Russian Federation can be calculated with the use of the recommended evaluation methods according to Table 1 - evaluation and calculation of norms for social-economic losses in road accidents [1].

* Corresponding author: pamspb@yandex.ru 
Table 1. Evaluation and calculation norms of social-economic losses from road traffic accidents.

\begin{tabular}{|c|c|c|c|}
\hline \multirow{2}{*}{$\begin{array}{c}\text { Consequences of road } \\
\text { traffic accidents }\end{array}$} & \multicolumn{3}{|c|}{$\begin{array}{c}\text { Social-economic losses from road traffic } \\
\text { accidents, in million rubles, by years }\end{array}$} \\
\cline { 2 - 4 } & $\mathbf{2 0 0 8}$ & $\mathbf{2 0 0 9}$ & $\mathbf{2 0 1 0}$ \\
\hline Death of a human being & 8.693 & 8.693 & 9.258 \\
\hline Wounding of a human being & 0.265 & 0.265 & 0.282 \\
\hline Death of a child & 10.516 & 10.516 & 11.200 \\
\hline
\end{tabular}

The developed European countries have decreased the social risk to be killed in road traffic accidents by tens of times, up to $3-5$ persons per 100 thousand of people, and today Russia faces the problem that each per cent in the reduction of road accidents will take more and more effort [2]. That is why the authorities at all levels should employ the scientifically feasible methods to discover the reasons of the high number of casualties in road traffic accidents at any point in the complex "driver-vehicle-road-environment" (DVRE), as guidelines to significantly decrease the lethality rates.

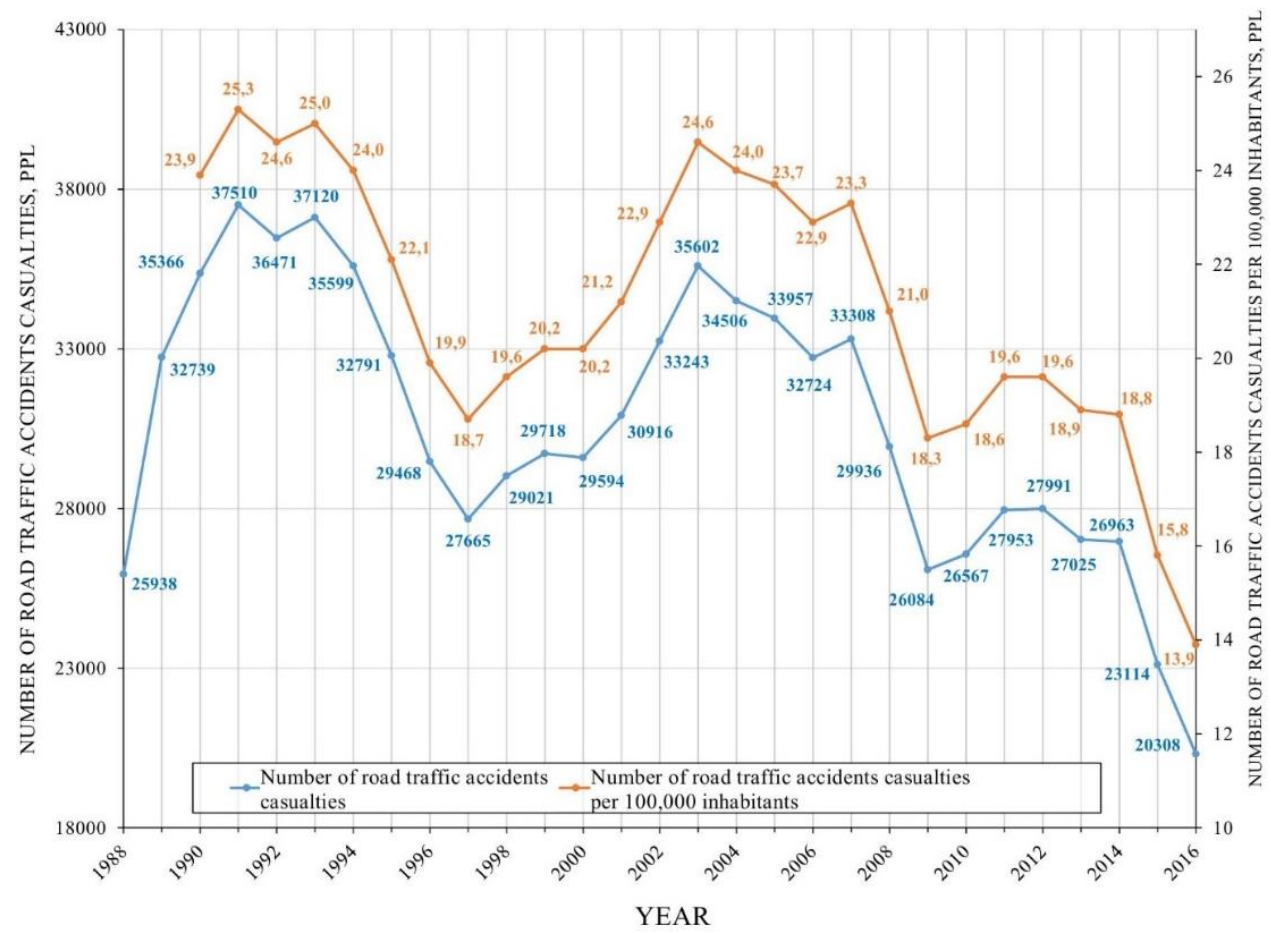

Fig. 1. Statistics of lethality in road traffic accidents during the latest 29 years in absolute and relative units in the territory of the Russian Federation.

The results and conclusions obtained from the research work conducted by the order of Saint-Petersburg administration can prove these facts [7]. This research has discovered that the lethality is above $20 \%$ in the currently functioning regulated road intersections (RRI) alone. These results are scientifically substantiated during the development of a low-cost methodology to ensure traffic safety at regulated road intersections of road networks in metropolitan cities [8], as presented in Figure 2 - by a functional flowchart of the results of the investigation. The methodology is a totality of the developed methods that are functionally related to the common cause to significantly decrease lethality in road traffic accidents with the widely used automated traffic control systems (ACS) at RRI (block 1 highlighted by a dashed line in Figure 2) due to the use of innovative solutions in traffic 
management schemes (TMS) with conflicting events (CE). For such TMS with CE we have developed the control methods for conflicting load ratios with new methods of the diagnostic (RPl) and updated (RPlmax) evaluation of traffic safety (TrS) within the framework of the developed conceptual system (block 2) for the level of requirements for the traffic safety (LRTrS) in accordance with the intervals of traffic safety presented in Table 2 [11] and with consideration of the classification [9] according to the methodic of the generalized algorithm for investigation of various TMS with CE at RRI by the methods of traffic control VPS, LRTrS and TrC. For comparative analysis in the investigation (blocks 2 and 4) we used traditional methods for evaluation of traffic safety (TrS), i.e. the currently used methods Ka - by MADI/Lobanov E.M., RShel - by NITs of GAI of MIA of RF (Scientific and Research Center of Traffic Police of Ministry of Internal Affairs of Russia) /Shelkov J.D. and the newly developed RPl, RPlmax - by SPSUACE /Plotnikov A.M. [2].

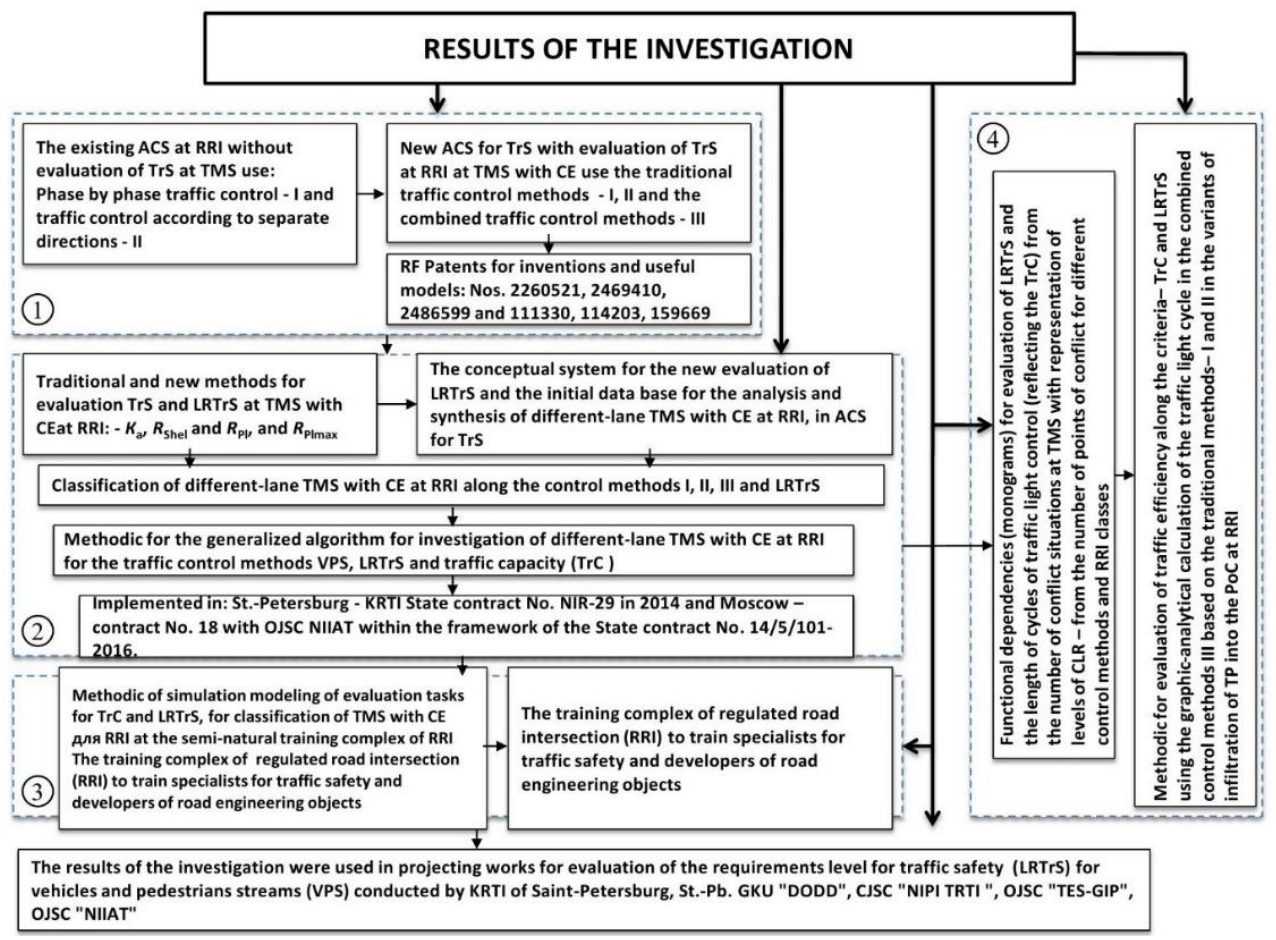

Fig. 2. Functional flowchart of the investigations results.

The investigations of ACS with conflict situations in TMS with CE at RRI were conducted both by the traditional control methods $(I)$ - with phase by phase control, and (II) - with control according to separate directions of traffic [4,5,6,13], and along the new method of combined traffic control (III) [10]. The method III can combine the traditional methods $I$ and $I I$ in one cycle of the traffic light control in ACS at RRI to provide the limits for the level of requirements for traffic safety and the required traffic capacity. At the same time, the method III ensures the automated minimizing of the number of conflict situations $[1,12,14,15]$ (points of conflict), as allowed by the Traffic Regulations of the RF for maneuvering in the vehicles and pedestrians streams (VPS) at RRI. 
Table 2. Quantitative conceptual system for evaluating $\operatorname{TrS}-K_{\mathrm{a}}, R_{\text {Shel }}, R_{\mathrm{Pl}}, R_{\mathrm{Plmax}}$.

\begin{tabular}{|c|c|c|c|c|}
\hline $\begin{array}{c}\text { Currently used evaluation - Ka } \\
\text { (RShel) units }\end{array}$ & below 3 & $\mathbf{3 . 1 - 8}$ & $\mathbf{8 . 1 - 1 2}$ & above 12 \\
\hline $\begin{array}{c}\text { Types of danger level (degree) of the } \\
\text { road intersection or level of the } \\
\text { conflicting events [4] }\end{array}$ & No danger & Low danger & Danger & High danger \\
\hline $\begin{array}{c}\text { Newly developed updated evaluation }- \\
\text { Ka, RShel, RPl,RPlmaxunits }\end{array}$ & $0-\leq 3$ & $>3-\leq 8$ & $>8-\leq 12$ & $>12$ \\
\hline $\begin{array}{c}\text { The conceptual system of levels of } \\
\text { requirements for traffic safety (LRTrS) } \\
\text { replacing the currently used types [3] }\end{array}$ & $\begin{array}{c}\text { Increased(In } \\
\text { crLRTrS) }\end{array}$ & $\begin{array}{c}\text { Intermediate(I } \\
\text { ntermLRTrS) }\end{array}$ & $\begin{array}{c}\text { Acceptable(A } \\
\text { ccLRTrS) }\end{array}$ & $\begin{array}{c}\text { Inacceptable(In } \\
\text { accLRTrS) }\end{array}$ \\
\hline
\end{tabular}

\section{Conclusions according to the results of the investigation}

In order to detect the reasons for road traffic accidents at single-level regulated and nonregulated road intersections (RRI and NRRI) within the scope of road networks of any city, town or township both in the RF and abroad a scientifically substantiated method can be used for low-cost diagnostic audit (when the traffic intensity VPS is not required - only the types and quantities by the types of points of conflict at TMS with CE are required) of LRTrS [2] ( $\left.\mathrm{R}_{\text {Plmax }}\right)$. The audit can be called the inventorying of traffic safety along the set norms (e.g., as shown in Table 2) with the corresponding records of the results level required by the customer for traffic safety out of the set range: IncrLRTrS, IntermLRTrS or AccLRTrS.

If an inacceptable level of requirements for traffic safety is detected during the diagnostic works for a single-level RRI or NRRI, the modernization is immediately ordered for the road section related to traffic accidents. During the modernization, an updated calculation shall also be conducted for the ensured level of $\operatorname{TrS}\left(R_{\mathrm{Pl}}\right)$ [2].

The recommended period for repeated inventorying for LRTrS at RRI and NRRI is 3-5 years.

\section{References}

1. A.P. Buslayev, Probabilistic and Simulative Approaches to Optimizing Motor Road Traffic. In: BuslayevA.P., Novikov A.V., Prikhodko V.M., Tatashev A.G., Yashina M.V., editors. Under supervision of Correspondent Member of Russian Academy of Sciences PrikhodkoV.M. Moscow: Mir publishers, 368 p. (2003)

2. European Report on the State of Traffic Safety/VOZ, 161 p. (2009)

3. Guidelines for Eliminating and Prevention of Sections of Increased Rate of Road Traffic Accidents during the Operation of Motor Roads (Version 2)/Federal Road Agency (Rosavtodor). Moscow (2008)

4. V.I. Konoplyanko, Road Traffic Management and Safety: Study book. In: Konoplyanko VI, editors. Moscow: Vysshaya Shkola publishers, 383 p. (2007)

5. J.A. Kremenets, Technical Means of Road Traffic Management: Textbook for Higher Schools. In: Kremenets J.A., Petchersky M.P., Affanassyev M.B., editors. Moscow: IKTs Akademkniga, 279 p. (2005)

6. E.M. Lobanov, Road Planning in Cities. In: Lobanov EM.Moscow: Transit, 194 p. (1990) 
7. A.M. Plotnikov, Managing Traffic Safety at Single-Level Road Intersections. Theory and Practice. Scientific Publication: Monograph. In: Plotnikov AM, editors. St.-Pb.: Expertnye Resheniya publishers, 404 p. (2014)

8. A. M. Plotnikov, Methodology for Ensuring Traffic Safety at Regulated Road Intersections in Megacities. Dissertation Abstract for Engineering Doctorate: 05.22.10. Saint-Petersburg: SPbGASU, 34 p. (2016)

9. A. Plotnikov, Y. Kotikov, P. Kravtchenko, Classification Investigations of Traffic Management Schemes Having Conflict Loading at the Signal-Controlled Road Junctions. Transportation Research Proceedings. 12th International Conference, pp. 511- 515 (2017)

10. A.M. Plotnikov, On the Unused Capability for Modernization of Technologies for Designing Regulated Road Intersections. In: Plotnikov AM, editors. Road Traffic Safety: Collection of Scientific Research Articles. FKU NITs for TrS of MIA of Russia, pp. 106-113 (2012)

11. Recommendations for Ensuring Traffic Safety in Motor Roads: ODM 218.4.005-2010: approved by the order of MinTrans (Ministry of Transport) of the RF dated 24.06.2002 No. OS-557-p: inst. of VSN 25-86; effective from 24.06.02//Web collection of legal and normative-technical documentation. - Access mode: http//docs.cntd.ru/document/1200084056. (2010)

12. Reference Book on Traffic Safety. Under supervision of Professor Silyanov V.V. OSLO: Transportøkonomistt. (Russian translation -2001), 754 p. (1997)

13. Road Traffic Management in Cities: Methodological Guidelines. Under general supervision of Shelkov JD.Scientific Research Center of GAI of the MIA of Russia. Moscow, 143 p. (1995)

14. D.S. Samoilov, City Road Traffic Management and Safety, Study book for higher schools. In Samoilov D.S. and Judin V.A. editors. Moscow: Vysshaya Shkola publishers, 256 p. (1972)

15. V. Zyryanov, Transport planning and simulation for FIFA world cup 2018 in Rostovon-Don Russia. In Proceedings of the 19th Intelligent Transport Systems World Congress, ITS 2012 Scopus. TU-00676 (2012) 